\title{
Pacific Tropics Are Warmer than Atlantic
}

\author{
Kern E. Kenyon \\ 4632 North Lane, Del Mar, USA \\ Email: kernken@aol.com
}

How to cite this paper: Kenyon, K.E. (2017) Pacific Tropics Are Warmer than Atlantic. Natural Science, 9, 27-30. https://doi.org/10.4236/ns.2017.92003

Received: January 17, 2017

Accepted: February 21, 2017

Published: February 24, 2017

Copyright $\odot 2017$ by author and Scientific Research Publishing Inc. This work is licensed under the Creative Commons Attribution International License (CC BY 4.0).

http://creativecommons.org/licenses/by/4.0/

\begin{abstract}
Pacific tropics are warmer than Atlantic tropics. This can be seen immediately from a world's sea surface temperature atlas, but readings from it of the latitudinal bandwidths between $80 \mathrm{~F}$ isotherms in the open waters of both oceans make this result very clear. Explanations are offered by introducing what has already been proposed for the large-scale surface circulations of the Pacific and incorporating conjectures for the circulation of the upper layer of the South Atlantic.
\end{abstract}

\section{Keywords}

Tropics, Atlantic, Pacific, SSTs, Cross-Equatorial Currents

\section{Introduction}

In the western tropics of the South Pacific, the highest SSTs of the whole Ocean are always found. Remarkably these sea surface temperatures are not significantly higher in the southern summer than in winter. Follow this observation followed predictions, based on the heat balance of the surface layer, waiting to be verified by new measurements [1]. Much more SST data exist in the North Pacific from which similar, rather powerful, predictions were originally generated [2].

With the analyses of above printed data and interpretations in place, the Atlantic Oceans are now approached with certain logical expectations, to summarize: surprises are found starting with the South Atlantic.

First, the tropics of the Pacific are warmer than those of the Atlantic. Why should that be? One measure of the difference between the oceans is that the mean latitude bandwidth of the two $80 \mathrm{~F}$ isotherms is more than twice as large (around 40 degrees) in the Pacific as it is in the Atlantic (around 20 degrees) throughout the year (Figure 1). This can be no accident, nor a consequence of inadequate data, and it is not predicted to the best of my knowledge.

Second, there are always two $80 \mathrm{~F}$ contours in the Pacific, one in each ocean with the equator in between. Although there are also two $80 \mathrm{~F}$ contours in the 


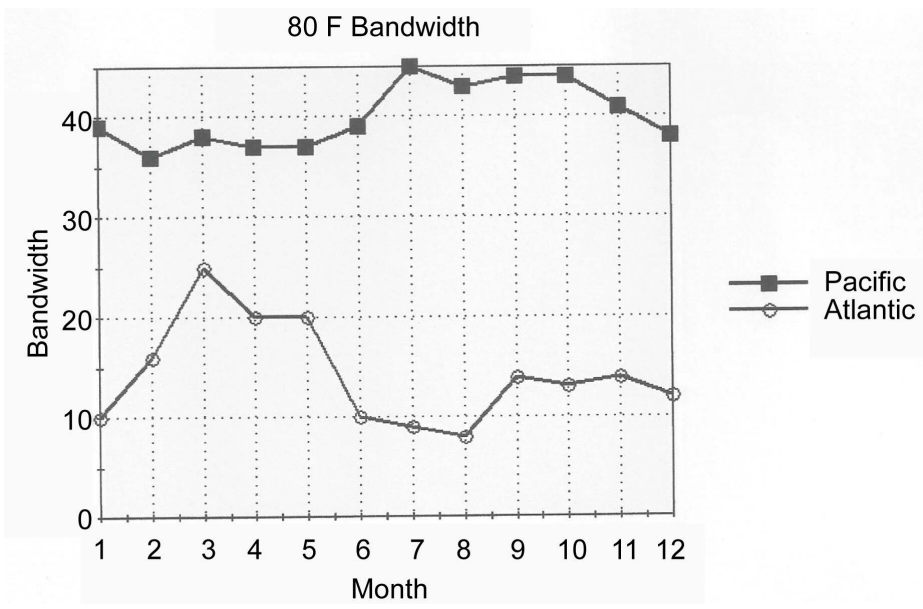

Figure 1. Mid-ocean bandwidths (degrees of latitude) for $80 \mathrm{~F}$ isotherms in the Pacific (upper) and Atlantic (lower) as a function of month (1 = January, etc.), based on data from Reference [2].

Atlantic, their distribution is not the same since in 8 months of the year, the southern contour is found to cross the equator at least once, and is nearly entire north of the equator in 6 of those months. That is enough time to strongly suggest that some cross-equatorial flows are likely to take place in the Atlantic [There is no comparable evidences for cross-equatorial flow in the Pacific].

Extending our understanding of the coolness of the Atlantic tropics compared with the warmth of the Pacific tropics could lead to practical consequences. For example, one might be able to get a better grip on climate changes, and directly monitoring the location of the equatorial crossing of the $80 \mathrm{~F}$ isotherm in the Atlantic could be a sensitive feature to be used as a tool. Monitoring polar features is a less habitable occupation.

\section{Figure Guide}

To construct Figure 1 the old world atlas of sea surface temperatures was consulted [3]. Latitudinal bandwidths between $80 \mathrm{~F}$ temperature contours were read off at five consecutive longitudes in the open ocean, with spacing between readings of five longitude degrees, and then averaged for each of the twelve months. Readings started at $160 \mathrm{E}$ in the Pacific, at $45 \mathrm{~W}$ in the Atlantic, and proceeded eastward from them. Without even doing this much work the main result, that the tropical Pacific is warmer than the tropical Atlantic, can be seen at a glance by turning the pages of the atlas. However, being a bit quantitative was judged to be a good thing, and the classical atlas is not available to most readers. Two observations of a more minor nature follow.

In Figure 1, the Pacific (upper) curve suggests no seasonal variation, or at best a very faint one. An explanation of the lack of that characteristic is available based on previous studies [1] [2]. The poleward swelling of the $80 \mathrm{~F}$ isotherms in spring and summer are 180 degrees out of phase in the two hemispheres. When the northern $80 \mathrm{~F}$ isotherm is moving north in the northern spring and summer, the $80 \mathrm{~F}$ isotherm in the southern hemisphere is returning north in the southern 
fall and winter. Thus, the bandwidth between the two $80 \mathrm{~F}$ isotherms remains nearly constant throughout the annual cycle. Since neither individual $80 \mathrm{~F}$ curves of latitude versus month is perfectly sinusoidal, the resulting bandwidth between them does not come out to be exactly a straight line. In a perfect world the 180 degree phase shift should be exact because it is imposed by the sun's regular movement.

Despite the factor of two smaller mean value of the Atlantic (lower) curve, compared to the Pacific curve, there is a bit more of an indication of a seasonal variation in this curve. In fact, a half period can perhaps be justified, six months instead of twelve. It is as if the two hemispheres in the tropical Atlantic are interfering with each other rather than cooperating like in the tropical Pacific, at least from the point of view of the $80 \mathrm{~F}$ bandwidth.

\section{Discussion}

How does an $80 \mathrm{~F}$ isotherm, at the sea surface, go from the South Atlantic where it resides for some months, to being partly or mostly in the North Atlantic in some other months, in which there is already an $80 \mathrm{~F}$ isotherm existing at all times? Movement of sea surface isotherms in the tropics is more likely to be an indication of surface currents than in other ocean regions because the exchange of heat from the ocean, due to initially absorbed solar radiation, back to the atmosphere is expected to be minimal. Then does the southern $80 \mathrm{~F}$ isotherm get pushed north and be caused to advect across the equator? If any pushing is to be done, it is probably by colder water moving north in the surface layer toward the equator form higher southern latitudes. By higher latitude is meant something like $35 \mathrm{~S}$, which parallel is tangent to the southernmost tip of Africa.

Consistent with this idea is the fact that the southern $80 \mathrm{~F}$ isotherm reaches its farthest position north of the equator in July and August, which is in the middle of the southern hemisphere winter. For example, along $20 \mathrm{~W}$ that isotherm reaches $6 \mathrm{~N}$ in July and in August $8 \mathrm{~N}$. Further substantiation of the conjecture may be difficult or impossible to attain with presently available data.

Using the shape and orientation of SST isotherms as indicators of surface current movement has a fairly long history, and it is not just restricted to low latitudes. As one example, open the temperature atlas to the first chart: the Atlantic oceans for January. Look in the middle of the South Atlantic at the $75 \mathrm{~F}$ isotherm. For 18 degrees of latitude, starting at $11 \mathrm{~S}$ and going south, the isotherm wanders about a longitude line (around 12 or $13 \mathrm{~W}$ ), so that it is more nearly vertical than horizontal! Under open ocean conditions that is unexpected. Could it be a mistake by the draftsman? Probably not. Two different isotherms to the east, and two to the west of the $75 \mathrm{~F}$ isotherm have vertical stretches just as prominent. February has similar regions where the isotherms are more nearly north/south, but in all months there are marked sloping segments of the isotherms.

Well known is the idea that if it were up to the sun alone, the isotherms should be parallel to lines of constant latitude. Such statements were put down in 
print off and on at least ever since Humboldt's time [4]. A surface current going east/west will not make an isotherm slope or turn vertical; there must be a north/south component to it.

Fitting in with these observations is the notion that the cold equatorward flow and warm poleward flow are moving side by side in the South Atlantic, in contrast to the Pacific where evidence suggests a more vertically stacked arrangement with wide warm poleward flows above cold return flows underneath. In other words, cold northward flows in the South Atlantic are more exposed to the surface, and this may be the main reason that the Atlantic tropics in particular are colder than the Pacific tropics are. Explanations for the side by side solution to the heat balance problem will hopefully come in the future. One naturally wonders why the vertical stacking configuration takes place in the wider ocean whereas the side by side arrangement apparently occurs in the narrower ocean. Also unclear at present for the surface circulation of the South Atlantic, after studies of the Pacific have already been made, is: what is the nature of the permanent wide warm and cold current systems in relation to the seasonal one?

\section{Conclusions}

Sea surface temperatures equal to or greater than $80 \mathrm{~F}$ occur in the tropics of the Pacific and Atlantic Oceans in all months, but the latitudinal bandwidth of those regions is twice as large in the Pacific as it is in the Atlantic on the average, based on data displayed in a world atlas of SSTs. This result is explained by differences in the large-scale surface circulations of the Pacific and Atlantic that are involved with the heat balances of those oceans.

Practical applications of the main observational result include increased understanding of climate changes by monitoring the locations of equatorial crossings of the $80 \mathrm{~F}$ isotherm in the Atlantic.

\section{References}

[1] Kenyon, K.E. (2016) South Pacific's Non-Seasonal SSTs. Natural Science, 8, 553556. https://doi.org/10.4236/ns.2016.812054

[2] Kenyon, K.E. (2015) Non-Seasonal SSTs of the Western Tropical North Pacific. Natural Science, 7, 605-612. https://doi.org/10.4236/ns.2015.713060

[3] No Authors (1942) World Atlas of Sea Surface Temperatures. 2nd Edition, H. O. 225, US Navy, Washington, DC.

[4] Humboldt, A. (1850) Cosmos: A Sketch of a Physical Description of the Universe. Harper and Brothers, 2, 281. 
Submit or recommend next manuscript to SCIRP and we will provide best service for you:

Accepting pre-submission inquiries through Email, Facebook, LinkedIn, Twitter, etc. A wide selection of journals (inclusive of 9 subjects, more than 200 journals)

Providing 24-hour high-quality service

User-friendly online submission system

Fair and swift peer-review system

Efficient typesetting and proofreading procedure

Display of the result of downloads and visits, as well as the number of cited articles Maximum dissemination of your research work

Submit your manuscript at: http://papersubmission.scirp.org/

Or contact ns@scirp.org 